\title{
Immature Granulocytes to Leukocytes Ratio Measurement
}

National Cancer Institute

\section{Source}

National Cancer Institute. Immature Granulocytes to Leukocytes Ratio Measurement. NCI Thesaurus. Code C100445.

The determination of the ratio of immature granulocytes compared to total leukocytes present in a sample. The measurement may be expressed as a ratio or percentage. 